\title{
Disease burden and prognostic factors for clinical failure in elderly community acquired pneumonia patients
}

Xiudi Han 1*, Xuedong Liu', Liang Chen², Yimin Wang ${ }^{3,4}$, Hui Li, ${ }^{3,4}$, Fei Zhou ${ }^{3,4}$, Xiqian Xing ${ }^{5}$, Chunxiao Zhang ${ }^{6}$, Lijun Suo ${ }^{7}$, Jinxiang Wang ${ }^{8}$, Guohua Y ${ }^{9}$, Guangqiang Wang ${ }^{10}$, Xuexin Yao ${ }^{11}$, Hongxia Yu ${ }^{12}$, Lei Wang ${ }^{13}$, Meng Liu' ${ }^{14}$, Chunxue Xue ${ }^{8}$, Bo Liư ${ }^{7}$ Xiaoli Zhu ${ }^{15}$, Yanli Li $i^{3,4}$, Ying Xiao ${ }^{3,4}$, Xiaojing Cui ${ }^{3,4}$, Lijuan Li $i^{3,4}$, Bin Cao ${ }^{3,4}$ and for the CAP-China network

\begin{abstract}
Background: The study was to evaluate initial antimicrobial regimen and clinical outcomes and to explore risk factors for clinical failure (CF) in elderly patients with community-acquired pneumonia (CAP).

Methods: 3011 hospitalized elderly patients were enrolled from 13 national teaching hospitals between January 1 , 2014 and December 31, 2014 initiated by the CAP-China network. Risk factors for CF were screened by multivariable logistic regression analysis.

Results: The incidence of CF in elderly CAP patients was $13.1 \%$. CF patients were older, longer hospital stays and higher treatment costs than clinical success (CS) patients. The CF patients were more prone to present hyperglycemia, hyponatremia, hypoproteinemia, pleural effusion, respiratory failure and cardiovascular events. Inappropriate initial antimicrobial regimens in CF group were significantly higher than CS group. Undertreatment, CURB-65, $\mathrm{PH}<7.3, \mathrm{PaO}_{2} / \mathrm{FiO}_{2}<200 \mathrm{mmHg}$, sodium $<130 \mathrm{mmol} / \mathrm{L}$, healthcare-associated pneumonia, white blood cells $>10,000 / \mathrm{mm}^{3}$, pleural effusion and congestive heart failure were independent risk factors for $C F$ in multivariable logistic regression analysis. Male and bronchiectasis were protective factors.

Conclusions: Discordant therapy was a cause of CF. Early accurate detection and management of prevention to potential causes is likely to improve clinical outcomes in elderly patients CAP.

Trial registration: A Retrospective Study on Hospitalized Patients With Community-acquired Pneumonia in China (CAP-China) (RSCAP-China), NCT02489578. Registered 16 March 2015, https://register.clinicaltrials.gov/prs/app/ action/SelectProtocol?sid=S0005E5S\&selectaction=Edit\&uid=U0000GWC\&ts=2\&cx=1 bnotb
\end{abstract}

Keywords: Community-acquired pneumonia, Clinical failure, Treatment pattern, Elderly

\footnotetext{
*Correspondence: hanxiudi@163.com

'Department of Respiratory Medicine, Qingdao Municipal Hospital Group, Jiaozhou Road, Qingdao City 266011, Shandong Province, China

Full list of author information is available at the end of the article
}

C C The Author(s). 2020 Open Access This article is licensed under a Creative Commons Attribution 4.0 International License, which permits use, sharing, adaptation, distribution and reproduction in any medium or format, as long as you give appropriate credit to the original author(s) and the source, provide a link to the Creative Commons licence, and indicate if changes were made. The images or other third party material in this article are included in the article's Creative Commons licence, unless indicated otherwise in a credit line to the material. If material is not included in the article's Creative Commons licence and your intended use is not permitted by statutory regulation or exceeds the permitted use, you will need to obtain permission directly from the copyright holder. To view a copy of this licence, visit http://creativecommons.org/licenses/by/4.0/ The Creative Commons Public Domain Dedication waiver (http://creativecommons.org/publicdomain/zero/1.0/) applies to the data made available in this article, unless otherwise stated in a credit line to the data. 


\section{Background}

Lower respiratory tract infections (LRTIs) fell to 4th place of global causes of deaths worldwide in 2016, yet community-acquired pneumonia (CAP) remains a leading cause of morbidity and mortality for hospitalization in LRTIs patients, especially for patients aged $\geq 65$ years [1-3]. After initiation of empirical antibiotic therapy, patients with CAP can experience different clinical outcomes, clinical improvement, clinical failure (CF) and non-resolving pneumonia. $\mathrm{CF}$ is a matter of great concern in the management of CAP. The incidence of CF among hospitalized patients with CAP ranges from 6 to $24 \%$ [4-8], and can reach up to $31 \%$ for patients with severe CAP [9]. CF leads to longer hospital stay and higher mortality $[4,5,9]$, longer duration of intravenous antimicrobial therapy [5], higher need for admission to intensive care unit (ICU) and more appearance of complications $[4,5]$.

Studies demonstrated that CF was due to an inadequate host-pathogen response, the initial severity of the infection, the presence of comorbidities, the causative organism, and the antimicrobial therapy administered $[4,5,9]$. Of which, underlying comorbidity [10, $11]$, severity of illness $[10,12]$ and antimicrobial regimen $[13,14]$ were independent factors for mortality of elderly hospitalized CAP. CF and mortality are the most relevant outcomes in elderly patients with CAP, yet there is rare discussion in literatures about its incidence and etiology.

It is crucial to understand the etiology of failure so as to implement different strategies at both national and local levels to prevent adverse outcomes. Therefore, we designed a retrospective study for hospitalized elderly CAP patients in order to identify the disease burden of $\mathrm{CF}$ and to explore the independent prognostic factors that predict failure to respond.

\section{Methods}

\section{Study setting, design and participants}

This study is a retrospective study utilizing patient and outcome data from the CAP-China network, which was a multicenter observational study of patients hospitalized with CAP. Data were abstracted from the database from January 1, 2014 to December 31, 2014 for all patients aged 65 years or older and included data from 13 centers in 7 cities of three provinces including Beijing, Shandong, and Yunnan (see Han et al. [15] for details concerning the patient cohort used in this study and the 'Availability of Data and Materials' section). The study was approved by the Human Subject Protection Program Institutional Review Board at China-Japan Friendship Hospital. Additional approval was obtained from the local internal review board for each participating hospital. Patient consent was waived due to the retrospective and observational study design. The initial antimicrobial regimen for each patient was evaluated and categorized as adherence, overtreatment, or undertreatment according to the 2016 Chinese CAP guidelines as previously described $[15,16]$. Patients were stratified into ICU or ward admission status based on their initial admission orders.

\section{Definitions}

CF was classified as early ( $\leq 72 \mathrm{~h}$ ) or late ( $>72 \mathrm{~h})$. Early $\mathrm{CF}$ was defined as patients within the first $72 \mathrm{~h}$ of hospital admission: (1) progressive pneumonia if clinical deterioration with acute respiratory failure requiring ventilator support and/or septic shock appears; (2) nonresponding pneumonia if persistence of fever and clinical symptoms without achieving clinical stability; and (3) death. Late CF was defined as patients after $72 \mathrm{~h}$ of initial antimicrobial treatment: (1) reappearance of fever with clinical deterioration (worsening of dyspnea with decrease of partial pressure of oxygen and/or increase of peripheral leukocyte count); (2) radiographic progression or the appearance of new infectious foci; (3) the need to switch to another antibiotic regimen resulting in an expansion of the antibiotic spectrum by adding another agent or replacing the initial antibiotic by another of the same class with a broader antibacterial spectrum and (4) death occurring after 30d of admission .

\section{Statistical analysis}

The patients were divided into CF group and clinical success (CS) group. Data were presented as frequencies or percentages for categorical variables and the mean \pm standard deviation for continuous variables. The characteristics of each group were compared using the $\mathrm{X}^{2}$ test for categorical variables and $t$ test for continuous variables.

Variables showing significant difference in univariate analysis $(p<0.20)$ were included in multivariate Logistic analysis model for CF, and a stepwise forward model was used to select independent risk factors. The 95\% confidence intervals (CIs) and level of significance were reported.

All data were analyzed with SPSS (version 20, IBM Corp., New York, USA); $p<0.05$ was considered statistically significant.

\section{Results}

\section{Incidence and baseline characteristics of clinical failure}

A total of 3011 patients aged $\geq 65$ years old were enrolled in final analysis. These following patients were excluded: (1) 62 patients of loss to follow-up; (2) 49 missing data on empirical antimicrobial regimens; (3)3 patients in the general ward who were administered antifungal agents and 6 patients in the ICU who were administered anti- 
pseudomonal $\beta$-lactam plus antifungal agents. CF occurred in $13.1 \%$ of elderly patients, 220 patients (55.7\%) were early failure. Table 1 showed the demographic characteristics, comorbidities and initial severity of disease, as calculated by CURB-65 and PSI. Compared with CS group, CF patients were older, higher risk of aspiration, long-term bedridden confinement and Pseudomonas aeruginosa infection and more comorbidity. The rates of congestive heart failure (CHF), bronchiectasis, cerebral vascular disease and chronic renal disease were significantly higher in CF patients. The pneumonia severity in CF patients was more severe than that in CS patients, and more patients were admitted to ICU. Sixty patients (15.2\%) reached to clinical stability on hospital admission, but still appeared failure.

\section{Clinical manifestations, laboratory and radiologic findings of clinical failure}

Compared to CS group, Table 2 showed the rates of wheezing, cyanosis and lower extremity edema were more common in CF group, as well as unstable vital signs. Hyperglycemia, azotemia, hyponatremia,

Table 1 Comparison of baseline characteristics in hospitalized elderly CAP patients with clinical failure and clinical success $(n=3011)$

\begin{tabular}{|c|c|c|c|}
\hline Characteristics & $C F(n=395)$ & $\operatorname{CS}(n=2616)$ & $p$ value \\
\hline Age (years) & $79.3 \pm 7.87$ & $77.1 \pm 7.3$ & $<0.001$ \\
\hline Male sex & $209(52.9)$ & $1431(54.7)$ & 0.516 \\
\hline Aspiration & $79(20.0)$ & $234(8.9)$ & $<0.001$ \\
\hline Long-term bedridden status & 74 (18.7) & $185(7.1)$ & $<0.001$ \\
\hline Underlying conditions & $381(96.5)$ & 2344 (89.6) & $<0.001$ \\
\hline Cardiovascular disease & $268(67.8)$ & $1607(61.4)$ & 0.014 \\
\hline Hypertension & $215(54.4)$ & $1262(48.2)$ & 0.023 \\
\hline Ischemic heart disease & $144(36.5)$ & $826(31.6)$ & 0.057 \\
\hline Congestive heart failure & $46(11.6)$ & $150(5.7)$ & $<0.001$ \\
\hline Chronic respiratory disease & $106(26.8)$ & $735(28.1)$ & 0.631 \\
\hline COPD & $77(18.5)$ & $482(18.4)$ & 0.627 \\
\hline Bronchiectasis & $17(4.3)$ & $273(10.4)$ & $<0.001$ \\
\hline Asthma & $16(4.1)$ & $139(5.3)$ & 0.330 \\
\hline Cerebral vascular disease & $141(35.7)$ & $641(24.5)$ & $<0.001$ \\
\hline Diabetes mellitus & $96(24.3)$ & $536(20.5)$ & 0.085 \\
\hline Malignancy & $35(8.9)$ & $205(7.8)$ & 0.485 \\
\hline Chronic renal disease & $37(9.4)$ & $114(4.4)$ & $<0.001$ \\
\hline Dementia & $11(2.8)$ & $44(1.7)$ & 0.154 \\
\hline Chronic liver disease & $5(1.3)$ & $33(1.3)$ & 1.000 \\
\hline History of CAP within 1 year & $52(13.2)$ & $207(7.9)$ & 0.001 \\
\hline HCAP & $135(34.2)$ & $385(14.7)$ & $<0.001$ \\
\hline Immunocompromise ${ }^{\#}$ & $18(4.6)$ & $52(2.0)$ & 0.004 \\
\hline Numbers of comorbidities & $2.4 \pm 1.4$ & $1.9 \pm 1.3$ & $<0.001$ \\
\hline \multicolumn{4}{|l|}{ Severity on hospital admission } \\
\hline CURB- $65^{\mathrm{a}}$ & $2.1 \pm 0.9$ & $1.5 \pm 0.7$ & $<0.001$ \\
\hline$\left.P S\right|^{b}$ & $118.0 \pm 32.2$ & $88.9 \pm 22.0$ & $<0.001$ \\
\hline ICU admission & $147(37.2)$ & $102(3.9)$ & $<0.001$ \\
\hline \multicolumn{4}{|l|}{ Outcomes } \\
\hline Clinical stability on hospital admission & $60(15.2)$ & $1015(46.4)$ & $<0.001$ \\
\hline Hospital LOS (days) & $16.4 \pm 17.0$ & $13.0 \pm 8.2$ & $<0.001$ \\
\hline Total cost (RMB, median) & $23,083.1$ & $12,287.5$ & $<0.001$ \\
\hline
\end{tabular}

Abbreviations: CF Clinical failure; CS Clinical success; COPD Chronic obstructive pulmonary disease; CAP Community acquired pneumonia; HCAP Healthcareassociated pneumonia; PSI Pneumonia severity index; ICU Intensive care unit; LOS Length of stay

\#definition seen as Han et al. [15]

${ }^{\text {a }}$ Figure urea nitrogen was missing in 124 cases. $n=2887$

${ }^{b}$ The total number of patients with a complete data of PSI score. $n=1666$ 
Table 2 Comparison of clinical manifestations, laboratory and radiologic findings in hospitalized elderly CAP patients with clinical failure and clinical success $(n=3011)$

\begin{tabular}{|c|c|c|c|}
\hline Characteristics & $C F(n=395)$ & $\mathrm{CS}(n=2616)$ & $p$ value \\
\hline \multicolumn{4}{|l|}{ Clinical features } \\
\hline Fever & $208(52.7)$ & $1364(52.1)$ & 0.871 \\
\hline Cough & $327(82.8)$ & $2368(90.5)$ & $<0.001$ \\
\hline Chest pain & $20(5.1)$ & $244(9.3)$ & 0.004 \\
\hline Wheezing & $214(54.2)$ & $1034(39.5)$ & $<0.001$ \\
\hline Cyanosis & $89(22.5)$ & $292(11.2)$ & $<0.001$ \\
\hline Lower extremity edema & $98(24.8)$ & $366(14.0)$ & $<0.001$ \\
\hline Mental confusion & $2016(26.8)$ & $137(5.2)$ & $<0.001$ \\
\hline $\mathrm{RR}>24$ beats $/ \mathrm{min}$ & $62(15.7)$ & $119(4.5)$ & $<0.001$ \\
\hline $\mathrm{HR}>125$ beats $/ \mathrm{min}$ & $34(8.6)$ & $40(1.5)$ & $<0.001$ \\
\hline Hypotension & $92(23.3)$ & $386(14.8)$ & $<0.001$ \\
\hline \multicolumn{4}{|l|}{ Laboratory findings } \\
\hline $\mathrm{WBC}>10,000 / \mathrm{mm}^{3}(n=2944)$ & $172(45.1)$ & 762 (29.7) & $<0.001$ \\
\hline The rate of $\mathrm{NE}(n=2917)$ & $0.8 \pm 0.2$ & $0.7 \pm 0.1$ & $<0.001$ \\
\hline The rate of $L(n=2890)$ & $0.1 \pm 0.1$ & $0.2 \pm 0.6$ & 0.007 \\
\hline $\mathrm{NE} / \mathrm{L}(n=2889)$ & $14.3 \pm 16.5$ & $7.1 \pm 9.4$ & $<0.001$ \\
\hline $\mathrm{HCT}<30 \%(n=2874)$ & $86(22.9)$ & $310(12.4)$ & $<0.001$ \\
\hline $\mathrm{Cr}>123.76 \mathrm{umol} / \mathrm{L}(n=2878)$ & $68(18.2)$ & $217(8.7)$ & $<0.001$ \\
\hline Glucose $>14 \mathrm{mmol} / \mathrm{L}(n=2757)$ & $19(5.5)$ & $68(2.8)$ & 0.013 \\
\hline $\mathrm{Na}<130 \mathrm{mmol} / \mathrm{L}(n=2890)$ & $55(14.7)$ & $141(5.6)$ & $<0.001$ \\
\hline $\mathrm{BUN}>7 \mathrm{mmol} / \mathrm{L}(n=2887)$ & $202(53.6)$ & $689(27.5)$ & $<0.001$ \\
\hline $\mathrm{PH}<7.3(n=1884)$ & $24(7.7)$ & $21(1.3)$ & $<0.001$ \\
\hline $\mathrm{PaO}_{2} / \mathrm{FiO}_{2}<200 \mathrm{mmHg}(n=1857)$ & $70(23.0)$ & $138(5.9)$ & $<0.001$ \\
\hline Albumin<25 g/L $(n=2863)$ & $57(15.7)$ & $154(6.2)$ & $<0.001$ \\
\hline \multicolumn{4}{|l|}{ Complications } \\
\hline Respiratory failure & $329(83.3)$ & $196(7.5)$ & $<0.001$ \\
\hline Arrhythmia & $60(15.2)$ & $45(1.7)$ & $<0.001$ \\
\hline Acute heart failure & $151(38.2)$ & $199(7.6)$ & $<0.001$ \\
\hline Acute myocardial infarction & $24(6.1)$ & $9(0.3)$ & $<0.001$ \\
\hline Acute liver failure & $27(6.8)$ & $17(0.6)$ & $<0.001$ \\
\hline Acute renal failure & $63(15.9)$ & $14(0.5)$ & $<0.001$ \\
\hline Stroke & $17(4.3)$ & $15(0.6)$ & $<0.001$ \\
\hline DIC & $4(1.0)$ & $1(0)$ & 0.001 \\
\hline Gastrointestinal bleeding & $47(11.9)$ & $21(0.8)$ & $<0.001$ \\
\hline Thromboembolic disease & $4(1.0)$ & $13(0.5)$ & 0.266 \\
\hline \multicolumn{4}{|l|}{ Radiology findings on CT } \\
\hline Multilobe infiltration $(n=3011)$ & $193(48.9)$ & $1181(45.1)$ & 0.178 \\
\hline Pleural effusion $(n=3011)$ & $146(37.0)$ & $603(23.1)$ & $<0.001$ \\
\hline
\end{tabular}

Abbreviations: $R R$ Respiratory rate; $H R$ Heart rate; $W B C$ White blood cell; $N E$ Neutrophil; L Lymphocyte; HCT Hematocrit; Cr Creatinine; Na Sodium; BUN Blood urea nitrogen; $\mathrm{PaO}_{2} / \mathrm{FiO}_{2}$. Partial arterial oxygen pressure/fraction of inspired oxygen; DIC Disseminated intravascular coagulation; CT Computed tomography hypoproteinemia, acidosis and pleural effusion were more prone to occur in CF patients. During the whole progress of hospitalization, the incidence of respiratory failure, acute cardiovascular events and acute renal failure was notably different between two groups.

\section{Pathogens}

Isolation of pathogens was defined in $73(18.5 \%)$ patients of CF group; 54 (74\%) patients isolated the gramnegative bacilli, and the top three pathogens were Pseudomonas aeruginosa (24.7\%, 18/73), Klebsiella pneumonia $(16.4 \%, 12 / 73)$ and Acinetobacter $(13.7 \%, 10 / 73)$. $17(23.3 \%)$ patients isolated the gram-positive cocci. Staphylococcus aureus $(15.1 \%, 11 / 73)$ was the most common pathogen, of which MRSA accounted for $90.9 \%(n=7)$. Streptococcus pneumoniae was isolated in only 2 patients and no atypical pathogen was found. 9.6\% $(\mathrm{n}=7)$ patients were isolated influenza virus and $19.2 \%(n=14)$ patients were mixed infections.

\section{Antimicrobial regimens}

Compared to CS group, the rate of inappropriate antimicrobial regimens was significantly higher in CF patients $(p<0.001)$. Table 3 showed that less than $30 \%$ of patients in CF group received initial treatment consistent with 2016 CAP guideline. Monotherapy with $\beta$-lactam in general ward or fluoroquinolone plus $\beta$-lactam in ICU was the most common regimen. The proportion of undertreatment and overtreatment was comparable in CF group. Regardless of CF group or CS group, the administration of anti-pseudomonal $\beta$-lactam accounted for a certain proportion.

\section{Outcomes}

A total of 167 (5.5\%) patients died during hospitalization, of which $41.9 \%(n=70)$ of patients died of early CF. 221 (7.3\%) died 30 days after discharge, although 35.7\% ( $n=$ 1075) of patients reached clinical stability on hospital admission. The mortality rate and 30d mortality rate was $11.6 \%(n=46)$ vs $16.7 \%(n=66), 14.1 \%(n=56)$ vs $18.5 \%$ $(n=73), 16.5 \%(n=65)$ vs $20.8 \%(n=82)$, respectively, in patients with treatment concordant to guideline, undertreatment and overtreatment in CF group.

Median overall treatment cost for one CAP episode was RMB 12,950.9 (mean \pm SD RMB 24,564.7 \pm 111 , 003.3). Treatment costs in successfully treated patients were below the overall median; however, they were nearly two-fold higher in failures $(\mathrm{p}<0.001)$. In CF group, median overall treatment cost for concordant patients was $\mathrm{RMB}$ 16,417.4 (mean $\pm \mathrm{SD} \mathrm{RMB}$ 46,714.9 \pm 96 , 721.8 ), slightly lower than that in overtreated patients, RMB 22348.2 (mean \pm SD RMB 47127.4 $\pm 63,894.2$ ), but significantly lower than that of undertreated patients, RMB 34098.5 (mean \pm SD RMB $70071.8 \pm 1,033,803.9$ ) 
Table 3 Comparison of antimicrobial regimens in hospitalized elderly CAP patients with clinical failure and clinical success ( $n=$ 3011)

\begin{tabular}{lll}
\hline Regimen & $C F(n=395)$ & CS $(n=2616)$ \\
\hline Consistent with guideline & $115(29.1)$ & $1032(39.4)$ \\
$\beta$-lactam & $76(19.2)$ & $579(22.1)$ \\
Fluoroquinolone & $22(5.6)$ & $368(14.1)$ \\
$\beta$-lactam + macrolide & $6(1.5)$ & $74(2.8)$ \\
$\beta$-lactam + fluoroquinolone & $22(5.6)$ & $11(0.4)$ \\
Undertreated by guideline & $138(34.9)$ & $396(15.1)$ \\
$\beta$-lactam & $99(25.1)$ & $302(11.5)$ \\
$\beta$-lactam + macrolide & $8(2.0)$ & $42(1.6)$ \\
Macrolide & $1(0.3)$ & $18(0.7)$ \\
Fluoroquinolone +/- $\beta$-lactam/other & $18(4.6)$ & $17(0.6)$ \\
Other combination & $12(3.0)$ & $17(0.6)$ \\
Overtreated by guideline & $142(35.9)$ & $1188(45.4)$ \\
Antipseudomonal $\beta$-lactam & $47(11.9)$ & $468(17.9)$ \\
Fluoroquinolone + $\beta$-lactam/ other & $71(18.0)$ & $585(22.4)$ \\
Antipseudomonal $\beta$-lactam+ macrolide & $6(1.5)$ & $45(1.7)$ \\
Antipseudomonal $\beta$-lactam + other & $11(2.8)$ & $52(2.0)$ \\
Fluoroquinolone + macrolide & $0(0)$ & $17(0.6)$ \\
$\beta$-lactam +quinolone+ other & $5(1.3)$ & $11(0.4)$ \\
$\beta$-lactam +macrolide+ fluoroquinolone /other & $2(0.5)$ & $10(0.4)$ \\
\hline
\end{tabular}

Note: other = imidazoles, lincomycin, etracyclines, aminoglycoside, fosfomycin, glycopeptides and antifungal agents

$(p=0.039)$. The median antimicrobial costs were RMB 2742.9, RMB 3624.3 and RMB 5365.1 in patients with treatment concordant to guideline, undertreatment and overtreatment of CF group ( $p=0.033)$. The median examination and hospitalization costs due to undertreatment were notably higher than concordant and overtreated patients $(p<0.02)$.

\section{Predictors related with clinical failure}

The multivariable Logistic model showed undertreatment $(p<0.001)$, CURB-65 $(p<0.001), \quad \mathrm{PH}<7.3(p<$ $0.001), \quad \mathrm{PaO}_{2} / \mathrm{FiO}_{2}<200 \mathrm{mmHg}(p<0.001), \quad \mathrm{Na}^{+}<130$ $\mathrm{mmol} / \mathrm{L}(p=0.001)$, healthcare-associated pneumonia (HCAP) $(p<0.001)$, white blood cells $(\mathrm{WBC})>10,000 /$ $\mathrm{mm}^{3}(p=0.002)$, plural effusion $(p=0.003)$ and CHF $(p=0.025)$ were independent predictors for CF related with elderly CAP patients. While male $(p=0.012)$ and bronchiectasis $(p=0.035)$ were protective factors (seen in Fig. 1).

\section{Discussion}

This is the first retrospective multicenter study to assess the disease burden of clinical failure in hospitalized elderly patients with CAP in China. The major findings of our study were as follows: 1) CF contributes to a significantly prolonged length of stay (LOS) and increased median overall treatment costs; 2)
Independent risk factors for $\mathrm{CF}$ were undertreatment, high CURB-65 score, lower $\mathrm{PH}$, lower $\mathrm{PaO}_{2} / \mathrm{FiO}_{2}$, hyponatremia, HCAP, leukocytosis, plural effusion and CHF; 3) Male and patients with bronchiectasis were associated with lower CF rate.

In our study, we adopted the term of clinical failure to include all patients whose condition deteriorated $[9,17]$. Although data from a prospective series of 1383 nonimmunosuppressed hospitalized adults with CAP demonstrated that older age ( $>65$ years) was an independent factor associated with clinical failure [5], the incidence of clinical failure in elderly hospitalized CAP patients in our study was $13.1 \%$, lower than that in previous studies $[4,5,8,9,18,19]$, mainly due to larger proportion of mild-to-moderate patients in our study.

The median overall treatment cost for one CAP episode was RMB 12,950.9 (mean \pm SD RMB 24,564.7 \pm $111,003.3)$. And they were nearly two-fold higher in CF patients, which was in accordance with previously published data [19]. Furthermore, we found median overall treatment cost in undertreated patients of $\mathrm{CF}$ group was significantly higher, which was mainly relative to extra examination and prolonged hospital stay. Patients experiencing CF required a significantly prolonged hospital stay compared with successfully treated patients (mean LOS $16.4 \pm 17.0$ versus $13.0 \pm 8.2$ days), which was similar to other studies from Switzerland [8], 


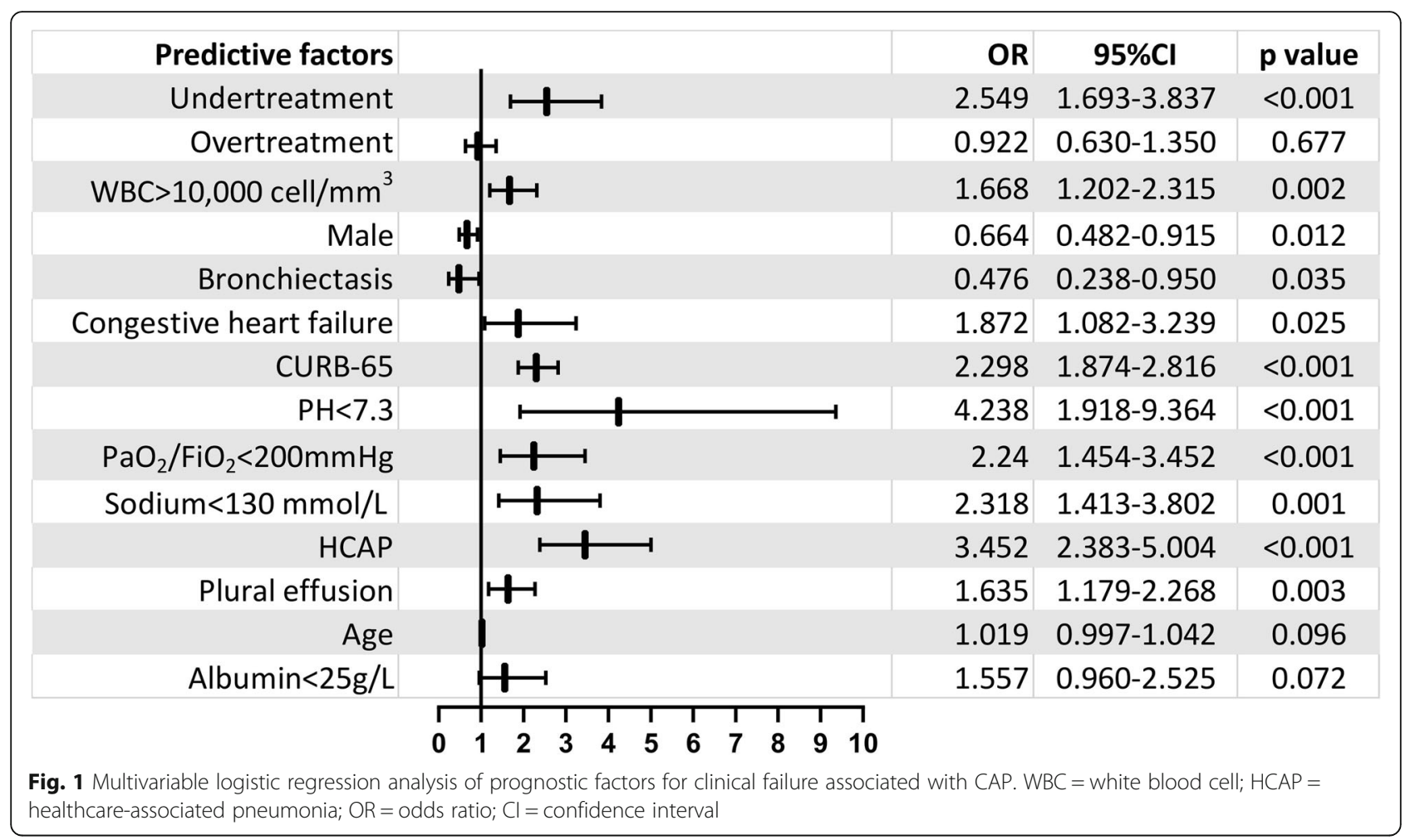

Netherlands [9] and Germany [19]. Prolonged hospital stay was associated with increased hospitalization costs. Our study demonstrated that CF patients, especially undertreated patients, were associated with significantly higher treatment costs. Thereby we postulate that any strategy to prevent discordant treatment and CF is of great interest in terms of medical cost savings.

Assessment in CF patients was more severe than CS patients, similar to outcome of recent studies [18, 19], and laboratory and imaging findings in our data also supported these information. Direct etiology of CF related to CAP was defined as causes with the pulmonary infection and the systemic inflammatory response; and medical complications, such as cardiac arrhythmia, acute myocardial infarction, or the deterioration of comorbidities, were resulted from CAP-related systemic inflammatory response [17]. From our data, acute cardiac events and other organ dysfunctions were more common in CF group than CS group, suggesting complications were causes leading to failure.

Although the CURB-65 score may underestimate severity and mortality in the lower scoring patients, especially the elderly [20], in our study, the CURB-65 score was identified to be an independent risk factor for CF. In previous literatures, more data showed PSI or APACHE II score was independent factor associated with failure $[4,5,21,22]$. Patients aged over 65 years old had more underlying comorbidity and poor outcome $[10,11,15,23]$; meanwhile, data in our study revealed patients in CF group also had more underlying comorbidity than successfully treated patients. Aliberti et al. had found that a history of cardiac disease and cardiac events was related with clinical failure in CAP patients [17]; physicians should pay more attention to prevent cardiac complications as well as further investigations for these patients. Data from our study demonstrated acute heart failure and arrhythmias were the most common cardiac events during hospitalization, and a history of congestive heart failure was responsible for clinical failure related to elderly CAP patients. Additionally, we also found a history of bronchiectasis was a protective factor for clinical failure. We considered that was associated with administration of anti-pseudomonal $\beta$-lactam. In our recently published report [15], data showed that Pseudomonas aeruginosa was the most common pathogen in elderly CAP patients, overuse of antipseudomonal $\beta$-lactam, to some extent, may lead to a certain concordant treatment.

Discordant treatment accounted for more than $70 \%$ in CF group, significantly higher than CS group, and both were higher than data from Roson et al. [5]. In the prospective observational analysis, discordant therapy in early failure only constituted 30.8\% [5]. Discordant treatment, especially overtreatment, is a very serious problem in China for CAP patients [15, 24]. In our study, some patients transferred from other hospitals or received antimicrobial treatment; therefore, the so-called initial antimicrobial treatment was not the really true initial 
treatment regimen. Part of the patients may have experienced clinical failure before admission. Wherefore a broad-spectrum antimicrobial treatment was prescribed after admission, resulting in overtreatment. Additionally, undertreatment was given for some patients due to inadequate assessment of severity and misjudgment of the pathogen.

Standardized antimicrobial treatment and a positive attitude toward guidelines is an urgent matter for all pneumology specialists. In our study, discordant treatment (undertreatment) was identified to be an independent risk factor for clinical failure, in accordance with previous data $[4,5,25]$.

In this study, the multivariable logistic analysis of independent risk factors to predict failure also concluded $\mathrm{PH}<$ 7.3, $\mathrm{PaO}_{2} / \mathrm{FiO}_{2}<200 \mathrm{mmHg}$, hyponatremia and plural effusion. These factors were easily acceptable for clinicians, because they are already known to be associated with a poor prognosis and higher score on the PSI [26] or CURXO [27] or SMART-COP [28]. Studies from Menendez et al. [4], Hoogewerf et al. [9] and Aliberti et al. [17] had the similar conclusion that above variables were associated with clinical failure. A prospective multicenter cohort study performed in 1424 hospitalized patients from 15 Spanish hospitals revealed that leucopenia was associated with an almost four-fold higher risk of treatment failure [4]. Kolling and coworkers found that leucocytes had a beneficial effect on antimicrobial activity and modulation of the pro-inflammatory cytokine response in CAP [29]. In contrast, leukocytosis $\left(\mathrm{WBC}>10,000 / \mathrm{mm}^{3}\right.$ ) was confirmed to be a prognostic factor for failure in our data. In one CAPNETZ study about the inflammatory markers, they found WBC levels were associated with increasing CRB-65 score, while CRB-65 score was associated with short-term and long-term mortality [30]. Our data had discovered CURB-65 was a prognostic factor for failure; therefore leukocytosis was easily acceptable as a predictor of failure. Previous studies about elderly CAP patients revealed that male sex was associated with higher mortality [31] and higher rate of re-hospitalization [31, 32]. Interestingly, multivariable analysis in this study showed that male was a protective factor for failure. We surmise there are maybe differences in both the biological response to infection and therapeutic patterns of health care on sex.

Our study has some limitations. The present study was a retrospective observational study, to some degree, there was bias on data which may affect certain analysis. Additionally, the rate of clinical failure is underestimated than that in the real world. Our previous study had showed that $42.3 \%$ of the elderly CAP patients had a documented history of pre-hospital medication ${ }^{15}$, and quite a few patients admitted to hospital was due to failure of pre-hospital antimicrobial treatment.

\section{Conclusions}

This is the first attempt to explore the burden and prognostic factor for clinical failure of hospitalized elderly CAP patients in China. For country of aging society, it is important to recognize risk factors early, strengthen the awareness and concept of standardized treatment and reduce or avoid inappropriate treatment. Strategies for improved patient care should be implemented for specialists.

\section{Supplementary information}

Supplementary information accompanies this paper at https://doi.org/10. 1186/s12879-020-05362-3.

Additional file $\mathbf{1}$ Table S1. Univariate logistic regression analysis of prognostic factors for clinical failure associated with CAP. $(n=3011)$.

\section{Abbreviations}

LRTIs: Lower respiratory tract infections; CAP: Community-acquired pneumonia; CF: Clinical failure; ICU: Intensive care unit; CS: Clinical success; Cls: Confidence intervals; PSI: Pneumonia severity index; CHF: Congestive heart failure; HCAP: Healthcare-associated pneumonia; WBC: White blood cell; LOS: Length of stay; $\mathrm{PaO}_{2} / \mathrm{FiO}_{2}$ : Arterial oxygen partial pressure / fraction of inspiration oxygen concentration; APACHE II: Acute physiology and chronic health evaluation II; CURXO: Confusion, urea nitrogen, respiratory rate, $\mathrm{x}$-ray, $\mathrm{PaO}_{2}$; CAPNETZ: Community-acquired pneumonia network

\section{Acknowledgments}

The authors are grateful for the contributions of all the staff of the CAPChina network for their help with data collection and input.

\section{Authors' contributions}

Study concept and design: $X \mathrm{dH}, \mathrm{XdL}$ and BC. Acquisition of data: $X \mathrm{dH}, \mathrm{LC}$, YmW, HL, FZ, XqX, CxZ, XdL, LjS, JxW, GhY, GqW, XxY, HxY, LW, ML, CxX, BL, $X I Z, Y I L, Y X, X j C$, and LjL. Statistical analysis of data: $X d H$. Drafting of the manuscript: $\mathrm{XdH}$. Critical revision of the manuscript for important intellectual content: BC. Study supervision: BC. All authors read and approved the study.

\section{Funding}

This work was supported by the National Science Grant for Distinguished Young Scholars (grant number 81425001/H0104), the National Key Technology Support Program from Ministry of Science and Technology (grant number 2015BAl12B11) and the Beijing Science and Technology Project (grant number D151100002115004).

\section{Availability of data and materials}

All data generated or analyzed during this study are included in this published article and its supplementary information files.

\section{Ethics approval and consent to participate}

This study was approved by the China-Japan Friendship Hospital Ethics Committee (2015-85). Given that the study was retrospective and all data were anonymous, the requirement for informed consent was waived.

\section{Consent for publication}

Not applicable.

\section{Competing interests}

The authors declare that they have no competing interests.

\section{Author details}

${ }^{1}$ Department of Respiratory Medicine, Qingdao Municipal Hospital Group, Jiaozhou Road, Qingdao City 266011, Shandong Province, China.

${ }^{2}$ Department of Infectious Disease, Beijing Jishuitan Hospital, Xinjiekou East Street, Xi-cheng District, Beijing 100044, China. ${ }^{3}$ National Clinical Research Center of Respiratory Diseases,Center for Respiratory Diseases, China-Japan Friendship Hospital, Beijing, China. ${ }^{4}$ Department of Pulmonary and Critical 
Care Medicine, China-Japan Friendship Hospital, Yinghuayuan East Street, Chao-yang District, Beijing 100020, China. ${ }^{5}$ Department of Respiratory Medicine, Yan'an Hospital Affiliated to Kunming Medical University, Renmin East Road, Kunming City 652199, Yunnan Province, China. ${ }^{6}$ Department of Respiratory Medicine, Beijing Huimin Hospital, Youanmen Street, West District, Beijing 100054, China. ${ }^{7}$ Department of Respiratory Medicine, Linzi District People's Hospital, Huangong Road, Zibo City 255000, Shandong Province, China. ${ }^{8}$ Department of Respiratory Medicine, Beijing Luhe Hospital, Capital Medical University, Xinhua South Road, Tongzhou District, Beijing 101149, China. ${ }^{9}$ Department of Pulmonary and Critical Care Medicine, Weifang No. 2 People's Hospital, Yuanxiao Street, Weifang City 261599, Shandong Province, China. ${ }^{10}$ Department of Respiratory Medicine, Shandong University Affiliated Qilu Hospital (Qingdao), Hefei Road, Qingdao City 266035, Shandong Province, China. " Department of Respiratory Medicine, The 2nd Hospital of Beijing Corps, Chinese Armed Police Forces, Yuetan North Street, Xi-cheng District, Beijing 100044, China. ${ }^{12}$ Department of Infectious Disease, Qingdao University Medical College Affiliated Yantaiyuhuangding Hospital, Yudong Road, Yantai City 100191, Shandong Province, China. ${ }^{13}$ Department of Respiratory Medicine, Rizhao Chinese Medical Hospital Affiliated to Shandong Chinese Medical University, Wanghai Road, Rizhao City 276800 , Shandong Province, China. ${ }^{14}$ Department of Respiratory Medicine, Beijing Hospital of Traditional Chinese Medicine Affiliated to Capital Medical University, Meishuguan Street, East District, Beijing 100010, China. ${ }^{15}$ Department of Occupational Medicine and Toxicology, Beijing Chao-Yang Hospital, Capital Medical University, Gongti South Road, Chao-yang District, Beijing 100020, China.

\section{Received: 4 April 2020 Accepted: 19 August 2020}

\section{Published online: 12 September 2020}

\section{References}

1. Petrosillo N, Cataldo MA, Pea F. Treatment options for community-acquired pneumonia in the elderly people. Expert Rev Anti-Infect Ther. 2015;13(4): 473-85.

2. de Miguel-Díez J, Jiménez-García R, Hernández-Barrera V, Jiménez-Trujillo I, de Miguel-Yanes JM, Méndez-Bailón M. Trends in hospitalizations for community-acquired pneumonia in Spain: 2004 to 2013. Eur J Intern Med. 2017:40:64-71.

3. Rivero-Calle I, Pardo-Seco J, Aldaz P, Vargas DA, Mascarós E, Redondo E, et al. Incidence and risk factor prevalence of community-acquired pneumonia in adults in primary care in Spain (NEUMO-ES-RISK project). BMC Infect Dis. 2017;17(1):64.

4. Menendez R, Torres A, Zalacain R, Aspa J, Martín Villasclaras JJ, Borderías L, et al. Risk factors of treatment failure in community acquired pneumonia: implications for disease outcome. Thorax. 2004;59:960-5.

5. Roson B, Carratala J, Fernandez-Sabe N, Tubau F, Manresa F, Gudiol F. Causes and factors associated with early failure in hospitalized patients with community-acquired pneumonia. Arch Intern Med. 2004;164:502-8.

6. Genne D, Kaiser L, Kinge TN, Lew D. Community-acquired pneumonia: causes of treatment failure in patients enrolled in clinical trials. Clin Microbiol Infect. 2003;9:949-54.

7. Arancibia F, Ewig S, Martinez JA, Ruiz M, Bauer T, Marcos MA, et al. Antimicrobial treatment failures in patients with community-acquired pneumonia: causes and prognostic implications. Am J Respir Crit Care Med. 2000;162:154-60.

8. Genne D, Sommer R, Kaiser L, Saaïdia A, Pasche A, Unger PF, et al. Analysis of factors that contribute to treatment failure in patients with community acquired pneumonia. Eur J Clin Microbiol Infect Dis. 2006;25:159-66.

9. Hoogewerf M, Oosterheert $J$, Hak E, Hoepelman IM, Bonten MJ. Prognostic factors for early clinical failure in patients with severe community acquired pneumonia. Clin Microbiol Infect. 2006;12:1097-104.

10. Luna CM, Palma I, Niederman MS, Membriani E, Giovini V, Wiemken TL, et al. The impact of age and comorbidities on the mortality of patients of different age groups admitted with community-acquired pneumonia. Ann Am Thorac Soc. 2016;13(9):1519-26.

11. Fernandez-Sabe N, Carratala J, Roson B, Dorca J, Verdaguer R, Manresa $F$, et al. Community- acquired pneumonia in very elderly patients: causative organisms, clinical characteristics and outcomes. Medicine. 2003;82(3):159-69.
12. Takayanagi N, Hara K, Tokunaga D. Etiology and outcome of communityacquired pneumonia in relation to age and severity in hospitalized adult patients. Nihon Kokyuki Gakkai Zasshi. 2006;44(12):906-15.

13. Dean NC, Bateman KA, Donnelly SM, Silver MP, Snow GL, Hale D. Improved clinical outcomes with utilization of a community-acquired pneumonia guideline. Chest. 2006;130(3):794-9.

14. Egger ME, Myers JA, Arnold FW, Pass LA, Ramirez JA, Brock GN. Cost effectiveness of adherence to IDSA/ATS guidelines in elderly patients hospitalized for community-Aquired pneumonia. BMC Med Inform DecisMak. 2016;16:34.

15. Han X, Zhou F, Li H, Xing X, Chen L, Wang Y, et al. Effects of age, comorbidity and adherence to current antimicrobial guidelines on mortality in hospitalized elderly patients with community-acquired pneumonia. BMC Infect Dis. 2018;18(1):192.

16. Cao B, Huang Y, She DY, Cheng QJ, Fan H, Tian XL, et al. Diagnosis and treatment of community-acquired pneumonia in adults: 2016 clinical practice guidelines by the Chinese thoracic society. Chinese Medical Association Clin Respir J. 2018;12(4):1320-60.

17. Aliberti S, Amir A, Peyrani P, Mirsaeidi M, Allen M, Moffett BK, et al. Incidence, etiology, timing, and risk factors for clinical failure in hospitalizedpatients with community-acquired pneumonia. Chest. 2008; 134(5):955-62.

18. Martin-Loeches I, Valles X, Menendez R, Sibila O, Montull B, Cilloniz C, et al. Predicting treatment failure in patients with community acquired pneumonia: a case-control study. Respir Res. 2014;15:75.

19. Ott SR, Hauptmeier BM, Ernen C, Lepper PM, Nüesch E, Pletz MW, et al. Treatment failure in pneumonia: impact of antibiotic treatment and cost analysis. Eur Respir J. 2012;39(3):611-8.

20. Schuetz P, Koller M, Christ-Crain M, Steyerberg E, Stolz D, Müller C, et al. Predicting mortality with pneumonia severity scores: importance of model recalibration to local settings. Epidemiol Infect. 2008;136:1628-37.

21. Gündüz C, Taşbakan MS, Sayıner A, Çilli A, Kılınç O, Şakar CA. Factors affecting treatment success in community-acquired pneumonia. Turk J Med Sci. 2016;46(5):1469-74.

22. Al-Rajhi A, Murad A, Li PZ, Shahin J. Outcomes and predictors of failure of non-invasive ventilation in patients with community acquired pneumonia in the emergency department. Am J Emerg Med. 2018;36(3):347-51.

23. Kaplan V, Angus DC, Griffin MF, Clermont G, Scott Watson R, Linde-Zwirble WT. Hospitalized community-acquired pneumonia in the elderly: age- and sex-related patterns of care and outcome in the United States. Am J Respir Crit Care Med. 2002;165(6):766-72.

24. Chen L, Zhou F, Li H, Xing X, Han X, Wang Y, et al. Disease characteristics and management of hospitalised adolescents and adults with communityacquired pneumonia in China: a retrospective multicentre survey. BMJ Open. 2018;8(2):e018709.

25. Menéndez R, Torres A, Zalacaín R, Aspa J, Martín-Villasclaras JJ, Borderías L, et al. Guidelines for the treatment of community-acquired pneumonia: predictors of adherence and outcome. Am J Respir Crit Care Med. 2005; 172(6):757-62.

26. Fine MJ, Auble TE, Yealy DM, Hanusa BH, Weissfeld LA, Singer DE, et al. A prediction rule to identify low-risk patients with community acquired pneumonia. N Engl J Med. 1997;336(4):243-50.

27. España PP, Capelastegui A, Gorordo I, Esteban C, Oribe M, Ortega M, et al. Development and validation of a clinical prediction rule for severe community-acquired pneumonia. Am J Respir Crit Care Med. 2006;174(11): 1249-56.

28. Charles PG, Wolfe R, Whitby M, Fine MJ, Fuller AJ, Stirling R, et al. SMART-COP: a tool for predicting the need for intensive respiratory or vasopressor support in community-acquired pneumonia. Clin Infect Dis. 2008:47:375-84

29. Kolling UK, Hansen F, Braun J, Rink L, Katus HA, Dalhoff K. Leucocyte response and anti-inflammatory cytokines in community acquired pneumonia. Thorax. 2001;56:121-5.

30. Krüger S, Ewig S, Giersdorf S, Hartmann O, Suttorp N, Welte T, et al. Cardiovascular and inflammatory biomarkers to predict short- and longterm survival in community-acquired pneumonia. Am J Respir Crit Care Med. 2010;182(11):1426-34.

31. Neupane B, Walter SD, Krueger P, Marrie T, Loeb M. Predictors of inhospital mortality and re-hospitalization in older adults with community-acquired pneumonia: a prospective cohort study. BMC Geriatr. 2010;10:22. 
32. Klausen $\mathrm{HH}$, Petersen J, Lindhardt $\mathrm{T}$, Bandholm $\mathrm{T}$, Hendriksen $\mathrm{C}$, Kehlet $\mathrm{H}$, et al. Outcomes in elderly Danish citizens admitted with communityacquired pneumonia. Regional differencties, in a public healthcare system. Respir Me. 2012;106(12):1778-87.

\section{Publisher's Note}

Springer Nature remains neutral with regard to jurisdictional claims in published maps and institutional affiliations.

Ready to submit your research? Choose BMC and benefit from:

- fast, convenient online submission

- thorough peer review by experienced researchers in your field

- rapid publication on acceptance

- support for research data, including large and complex data types

- gold Open Access which fosters wider collaboration and increased citations

- maximum visibility for your research: over $100 \mathrm{M}$ website views per year

At $\mathrm{BMC}$, research is always in progress.

Learn more biomedcentral.com/submissions 